\title{
The Design Trend of Modern Hospital Architecture
}

\author{
Na Wang ${ }^{1, a}$ and corresponding author: Jinguo Wang ${ }^{2, b, *}$ \\ ${ }^{1}$ Department of Anesthesiology, The First Hospital of Jilin University, Changchun, China \\ ${ }^{2}$ Department of Urology, The First Hospital of Jilin University, Changchun, China \\ awangna080613@163.com, bwangjinguolily@163.comil
}

Keywords: Modern, Hospital, Architecture, Design, Trend.

Abstract. The hospital is an important part of public infrastructure in the development of modern society. As a modern hospital, it should adhere to the principle of people-oriented and the service objective of modern hospital architecture design. On the base of theory and practice analysis, the trend of modern hospital architecture aims to put forward a new idea of modern hospital architecture design to adapt to the update and change of medical mode in China. Hospital construction should not only consider the comfort level, but also consider the actual use process. Therefore, in the process of the construction of hospital, the surrounding environment is the design scheme and the technique and equipment of the hospital should be investigated.

\section{Introduction}

Along with development and progress of the society, the hospital architecture design is more and more considered. In the current, to make the hospital applicable, economy, green and beautiful has become a common principle of hospital architecture design. [1] The construction space can assist medical treatment, which has been recognized by the public. It makes people pay more and more attention to the beauty of hospital architectural space.

The architectural beauty is reflected in the some aspects, including the formal beauty of the building itself, harmonious beauty of architecture and surrounding environment, the ecological beauty of architecture and natural environment. The architecture embodies the cultural beauty of regional characteristics and ethnic customs. The architecture expresses the spirit of the modern beauty of keeping pace with the time. [2]

\section{Intellectualized Practice of Hospital Building}

Basic Construction. In Chinese modernization process, hospitals need to focus on intelligent design trend of modern hospital building. The trend is gradually changing the traditional hospital overall layout structure and design method, with the application of comprehensive electronic information technology. The comprehensive modernization of the hospital has taken on a variety of ways to register rhyme, to see a doctor, to simplify the procedure of the patient's practice and physical demands. [3] In addition to this, intelligence is performed to get medicine time shortened, and the whole hospital operation and spatial design is the need for comprehensive management, thus it can be seen, information management and processing should also be intelligent layout, the location selection, space layout, the layout of the circuit layout and hierarchy is one of Chinese concept of generation of the practice of hospital building design trend. [4]

Innovative Attempt. Generally, the pattern of the hospital is divided into three parts, outpatient department, inpatient department and administrative department, the requirements of convenience. It should be evident in the outpatient department and close to the main road, traffic location good position and to improve medical treatment in patients with speed and efficiency. [5]

Hospital department is mainly for patients in hospital and family services, so you need to in the relatively quiet and beautiful environment position, on this basis, can be more innovative new pattern of the hospital, the hospital under the background of the larger, outpatient and inpatient department branch design, can be in hospital departments can also be set parallel in suburban environment is good. 
[6] The atmosphere is more suitable for tone area, separated from the position of the outpatient department, scattered large-scale traffic, it is beneficial to the recovery of the patients health, on the one hand, on the other hand can also help prevent the central position of high house prices and medical environment can't keep up with the problems caused by traffic jams. [7]

People-oriented Design Concept. Hospital buildings face the development and renewal of modern medicine. Today, hospital architecture is no longer just the place for treating and isolating patients. [8] In order to better serve the patients, the people who came to the hospital have a sense of security and trust in the hospital, and require the hospital buildings to be both lively and reasonable. [9]

Modern medicine believes that the patient's mental activity plays a significant role in the development of the disease. It can provide a comfortable and warm environment for patients to relieve tension, enhance confidence and thus promote treatment. [10]

Hospital culture. Hospital culture is a kind of cultural accumulation formed in the long-term development and medical practice of hospital. From the mode of production, it should be said that the inheritance is more than the reconstruction, and the refinement is more than the creation. In the sublimation, we become the consensus of the people and observe the ethics of behavior. [11]

In general hospital culture can be divided into basic culture, system culture, behavior culture, spirit culture, four levels and hospital capital construction work and the culture are inseparable relationship. [12] The most closely related is the basic culture, such as the construction of the overall environment of the hospital, the completion of the living facilities and the shaping of the courtyard and the courtyard, etc., which are the basic contents of the construction work. [13]

\section{Safe Environment}

For accidental injury of space environment, strategy can be summarized as: patients with perfect function layout to minimize unnecessary movement, as in the process of moving the supporting demand, create favorable positive nursing care environment. [14] Strategies for occupational exposure of space environment can be summarized as: measures to weaken the exposure by space environment, through building space layout control hazard scope, through the improvement of the medical operating environment control intrusion behavior, specific intrusive way of setting Angle of architecture technology barrier. [15]

Architectural point of view of medical safety rational thinking is a kind of demand of The Times. Of this study is devoted to the analysis architectural space environment factors affecting the safety of medical treatment, to provide relevant risk control on the basis of the theory and practice level. Medical security is a serious public health problem, is a matter of life and health, social stability. Frequent hospital security incident shows a stage of our country medical security level did not meet the demand of the safety of the people. [16]

Some designers do not understand the rules on the construction of hospitals, or are very familiar with hospitals. On the operation mode and in the process of design, they don't apply new materials to the hospital building, especially for patients living in the inside of the hospital with psychological problems. They don't very understand all of design of the hospital under the induction of the buildings. [17] The finished product can't be according to the desired effect and the need of hospital for medical work, so the hospital architectural design personnel in the design level is not professional, and because of our country most of the hospital building is built before, many designers can't innovate on the style, it is also one of the major problems, so the designer should pay attention to the cultivation of their ability.

\section{Conclusions}

The hospital must set out from two aspects of practicability and patients at the same time, in order to make our design more reasonable in the process of construction. The designer should take their accomplishment in this respect, let the hospital building has become more reasonable, so as to better 
service for patients. In the integral design of the hospital building, good design is not only the desire of the hospital, but also the desire of patients.

\section{References}

[1] Baltes M M. Environmental factors in dependency among nursing home residents: A social ecology analysis. Basic processes in helping relationships. 1982

[2] Isa Halim, Hambali Arep, Seri Rahayu Kamat, Rohana Abdullah. Development of a Decision Support System for Analysis and Solutions of Prolonged Standing in the Workplace[J]. Safety and Health at Work. 2014

[3] Morrill, Patricia W. Risk Assessment as Standard Work[J]. Health Environments Research \& Design Journal. 2013 (1)

[4] Jane A. Weintraub, Susan G. Millstein. Community preventive services and oral health[J]. American Journal of Preventive Medicine. 2002 (1)

[5] Guenther R, Vittori G. Sustainable healthcare architecture. 2008

[6] Verderber S, Fine D J. Healthcare architecture in an era of radical transformation. 2000

[7] Bin LI. Living Environment of Elderly Facilities in Shanghai. 13th Osaka City University International Symposium .

[8] Weiss J D. Better buildings for the aged. 1969

[9] Deborah Spratt. Workplace Safety Equals Patient Safety[J]. AORN Journal. 2012 (3)

[10] Atiya Mahmood, Habib Chaudhury, Alana Gaumont, Tiana Rust. Long-term care physical environments - effect on medication errors[J]. International Journal of Health Care Quality Assurance. $2012(5)$

[11] Dan R. Thompson, D. Kirk Hamilton, Charles D. Cadenhead. Guidelines for intensive care unit design[J]. Critical Care Medicine. 2012 (5)

[12] Jaynelle F. Stichler, Cyndi McCullough. Same-Handed Patient Room Configurations: Anecdotal and Empirical Evidence[J]. The Journal of Nursing Administration. 2012 (3)

[13] Moore G T. New directions for environment-behavior research in architecture. 1981

[14] Gharaveis, Arsalan, Shepley, Mardelle McCuskey. The Role of Daylighting in Skilled Nursing Short-Term Rehabilitation Facilities[J]. Health Environments Research \& Design Jour. 2016 (2)

[15] Rana Zadeh, Hessam Sadatsafavi, Ryan Xue. Evidence-Based and Value-Based Decision Making About Healthcare Design[J]. Health Environments Research \& Design Jour. 2015 (4)

[16] Young-Seon Choi, Sheila J Bosch. Environmental Affordances: Designing for Family Presence and Involvement in Patient Care[J]. Health Environments Research \& Design Jour. 2013 (4)

[17] Debra D Harris, Laura A Detke. The Role of Flooring as a Design Element Affecting Patient and Healthcare Worker Safety[J]. Health Environments Research \& Design Jour. 2013 (3) 